\title{
Social and behavioural responses during the COVID-19 pandemic in Bosnia and Herzegovina
}

\author{
ANA JANKOVIĆ 1 , MIA BAKAL 1 , ADNAN HADŽIAHMETOVIĆ 1 , LAMIJA \\ KOVAČEVIĆ 1 , NEJLA OMIĆ $1 \&$ SABINA ČEHAJIĆ-CLANCY2*
}

IDepartment of Political Science and International Relations, Sarajevo School of Science and Technology, Bosnia and Herzegovina

2Department of Psychology, Stockholm University, Sweden

Sarajevo Social Science Review

(under review)

Note: This is a preprint version of a manuscript that has not yet been peer reviewed for formal publication. It might be published in a different version in the future.

Version 1: June 2020

* Email: sabina.cehajic-clancy@psychology.su.se 


\begin{abstract}
In this paper we report results from an online study conducted in Bosnia and Herzegovina during the ongoing COVID-19 pandemic (May 2020). The study examined a range of social and behavioural responses by youth from different ethnic backgrounds and across 63 cities $(\mathrm{N}=569)$. More specifically, the study focused on investigating the relationship between threat perceptions, public health behaviours, stress and social cohesion. As expected, results indicate that higher perceptions of threat were related to higher compliance to safety and health measures despite extremely extremely low levels of political trust. Suprisingly, participants reported relatively low levels of stress despite high social isolation and physical restrictions. These results could partially be explained by an increased level of family interactions. Furthermore, participants reported relatively high levels of social cohesion and common-ingroup identification in a usually segregated and conflict-ridden context.
\end{abstract}

Keywords: COVID-19, Bosnia and Herzegovina, public health behaviour, political trust, social cohesion 


\section{Introduction}

On 31 December 2019, the World Health Organization received a report of a lunginflammation case of an unfamiliar cause, identified in Wuhan, in China. Later, it was discovered that such pneumonia was caused by a new highly contagious and infectious coronavirus (SARS-CoV-2). The disease caused by this virus was named COVID-19. On 30 January 2020, WHO declared Public Health Emergency of International Concern (PHEIC) (World Health Organization 2020a). Epidemic quickly turned into a global pandemic, which was officially declared by the World Health Organization (2020b) on 11 March 2020. On that day, there were 118,319 confirmed coronavirus cases in 114 countries and 4,292 registered deaths caused by the new virus (World Health Organization 2020c). As a result of the crisis, WHO issued prevention and control public health and social measures to be applied during the COVID-19 pandemic.

The first coronavirus case in Bosnia and Herzegovina was confirmed on 5 March 2020 (N1 2020). A state of emergency at the state-level was declared on 17 March 2020 by the Council of Ministers (2020). This has resulted in the implementation of the prevention and control measures and issuing of recommendations and guidelines by the governmental bodies at the entity and state level. In this paper, we report empirical evidence from a study conducted across 63 cities in Bosnia and Herzegovina during the ongoing COVID-19 pandemic. The study examined social and behavioural responses of the youth during the pandemic. More specifically, we measured perceived threat of the pandemic and its relation to behavioural adherence to proposed public health measures, reported stress levels as well as social cohesion.

Literature suggests that perceptions of threat are likely to lead to behavioral changes both at the individual and group level (Stephan and Srephan 2020). Health Belief Model (HBM) was developed to provide insights into health-related behaviors and to predict them. At the center of the model is a perception of threat. The HBM explains that behavioral response is determined by the evaluation of the threat's impact on a person's well-being. Furthermore, perception and assessment of threat is related to effectiveness produced by specific behaviors, in addition to several other factors. Thus, the willingness to respond is shaped by the perception of threat and behavioral evaluation (Abraham and Sheeran 2015). Another model with overlapping postulates with the HBM is the Protection Motivation Theory (PMT). This model was developed to provide insights into fear appeals and its consequent implications. According to the theory, attitude and assessment of the risk will be based on (at least) three factors: 
harmfulness (severity) od that specific event, the likelihood of it to occur, and the effectiveness of the protective behavior (Rogers 1975).

Considering the nature of events such as the COVID-19 pandemic, it can be anticipated that a large number of people will perceive it as highly threatening. The expected emotional response to this event could be fear. Additionally, literature suggests that emotional states can be contagious (Hatfield, Cacioppo and Rapson 1993). Even though in-person interaction is reduced to a minimum during the outbreak of a disease such as COVID-19, Kramer, Guillory, and Hancock (2014) contacted an experiment which proved that emotional contagion on a mass scale is possible via social networks; thus, for transmission of fear to occur, in-person interaction is not necessary. Therefore, this study will explore the perception of COVID-19 as thgreatenig and its relation to the fear emotion.

However, it is important to note that a perception of threat can vary from person to person as well as across and within social groups. This difference in perceived threat could produce different social and behavioral responses. High levels of threat could lead to an increased fear, leading people to change or adjust their behavior. If people feel capable and efficient enough to deal with the emotion of fear, produced by the imminence or perception of threat, constructive behavior changes might follow (Witte and Allen 2000). Correspondingly with the HBM and PMT models, the level of perceived threat could possibly have a significant impact on adherence to protective measures, where the increased perception of risk would produce the adoption of recommended protection and prevention public health measures. On the other hand, some people might hold to beliefs that bad things would not happen, leading people to underestimate the seriousnessness of the situation and ignore public health warnings. Van Bavel et al. (2020) explained this as optimism bias. Therefore, the study will seek to analyze the relationship between the perception of threat and adherence to public health measures, anticipating that people will more likely comply with recommended public health measures such as hand washing or maintaining physical distance if they perceive the situation as more threatening than those who do not.

Furthermore, as Khosravi (2020) explained, different factors can determine the level of risk awareness of an individual and the general public; one of these factors is trust. Siegrist and Zingg (2014) examined the relevance of trust during a pandemic. Applying Trust, Confidence, and Cooperation (TCC) model, they concluded that trust in bodies of authority has a positive effect on compliance with the recommended measures. In this study, we will also measure trust people hold toward specific and relevant institutions. We will seek to analyze the relationship 
between trust in relevant institutions and perceived threat, presuming that low levels of trust would be related to low-risk assessments.

Moreover and in relation to stress outcomes, pandemics such as the COVID-19 can act as a major stressor and produce a range of psychological difficulties from anxiety, sense of loneliness, or challenges in relationships. The outbreak of the disease has disrupted the everyday life of many people around the world. The factors such as economic difficulties, selfisolation, and social distancing can intensify these difficulties (Polizzi, Lynn and Perry 2020). As Baumeister and Leary (1995) demonstrated, the need to belong and to socially connect (establish and maintain stable relationships with other people), is an essential human motivation. Lack of such connections can produce and increase adverse psychological reactions (Polizzi, Lynn, and Perry 2020). Strategies to mitigate such issues could be an increased engagement in online interactions to foster a sense of social connections. Here, we will report experiences on different mental health indicators including changes in social interactions.

In addition to the above, we also aimed at measuring the potential effects of perceived threat on social cohesion indicators. As suggested by the literature, societal threat such as pandemics can have at least two outcomes for intergroup evalutions and relations. It can cause a range of negative social phenomena such as polarization, national isolation or scapegoating (Riek et al., 2006). Or it can lead to an increased intergroup solidarity and prosocial behaviour sue to perceptions of common shared destiny leading to increased common ingroup identifications. Thus, the pandemic could result in an augmentation of common identity perception. The source of sameness would be the same danger faced by everyone, which can induce a feeling of common fate (Van Bavel et al., 2020). Bosnia and Herzegovina, as a complex society, acts as a shared (yet seggregated) space for different ethnic and religious groups. In this research, we have measured inclusive and exlusive forms of identities and a range of prosocial behavioural responses during the COVID-19 pandemic . 


\section{Methodology}

\section{Participants}

A total of $569(\mathrm{~N})$ participants took part in the study. The sample included 376 females (64.5\%), 198 males (34.8\%), and 4 participants (.7\%) who reported gender as "other". The participants aged between 18 and $33(\mathrm{M}=21.46, \mathrm{SD}=1.93)$. As a place of residence, the participants reported 63 different cities. A total of 226 (39.7\%) participants identified as Bosniaks, $219(38.5 \%)$ as Bosnian-Herzegovinians, 45 (7.9\%) as both, Bosniaks and BosnianHerzegovinians, $35(6.2 \%)$ as Serbs, $18(3.2 \%)$ as Croats, $3(.5 \%)$ as Foreigners (but residing in $\mathrm{B} \& \mathrm{H}), 1(.2 \%)$ as Croat and Bosnian-Herzegovinian, and $22(3.9 \%)$ listed "other" as identity.

\section{Research design and procedure}

A study used both exploratory and confirmatory research design. It explored the impact of ongoing COVID-19 pandemic, a novel situation characterized as a global health crisis of our time, on some important social and behavioural indicators which we report below. The data were collected via an online survey over a period of eight days in May 2020 (May 6-14). Survey was uploaded using the Google Forms platform. The researchers came in contact with potential participants via e-mail and social networks. Participants who were contacted directly and consented to participate were asked to share the invitation among their contacts. Therefore, the sample was a combination of both convenience and snowball sampling method. The data were analyzed applying statistical methods in Statistical Package for the Social Sciences (SPSS).

\section{Materials}

The survey was designed to measure the impact of COVID-19 pandemic on healthy behaviour changes, stress and coping, and prosocial behaviour changes at the group level (social cohesion). Firstly, healthy behavior changes were evaluated by participants' selfreported adherence and support for recommended public health measures made by governmental bodies and specifically the World Health Organization. The questions were in the form of a Likert scale where participants evaluated the level of agreement with particular statements by choosing a number from 1 to 5 and 1 represented "strongly disagree", 2 "disagree", 3 "neither agree nor disagree", 4 "agree" and "strongly agree". Secondly, stress and coping mechanisms were measured with multiple items assessing the frequency of feeling specific stress symptoms. The participants were asked to self-assess it by choosing one of the following options: 1 "never", 2 "rarely", 3 "sometimes", 4 "often", or 5 "always". Thirdly, 
prosocial behaviour at a group level was measured by examining the level of social cohesion. The participants were asked about which group of people they were mostly concerned during the pandemic. Also, they were asked if they could to which group they would mainly help. The offered answers were: my neighborhood, my community, my entity, and all citizens of my country.

\section{Results}

Perception of threat

Overall, more than half of our participants reported that they perceived COVID-19 as a threat whereas $18,8 \%$ were not sure what to think. See figure 1 for the distribution of the results.

Figure 1

Percentage of young people perceiving COVID-19 as threatening

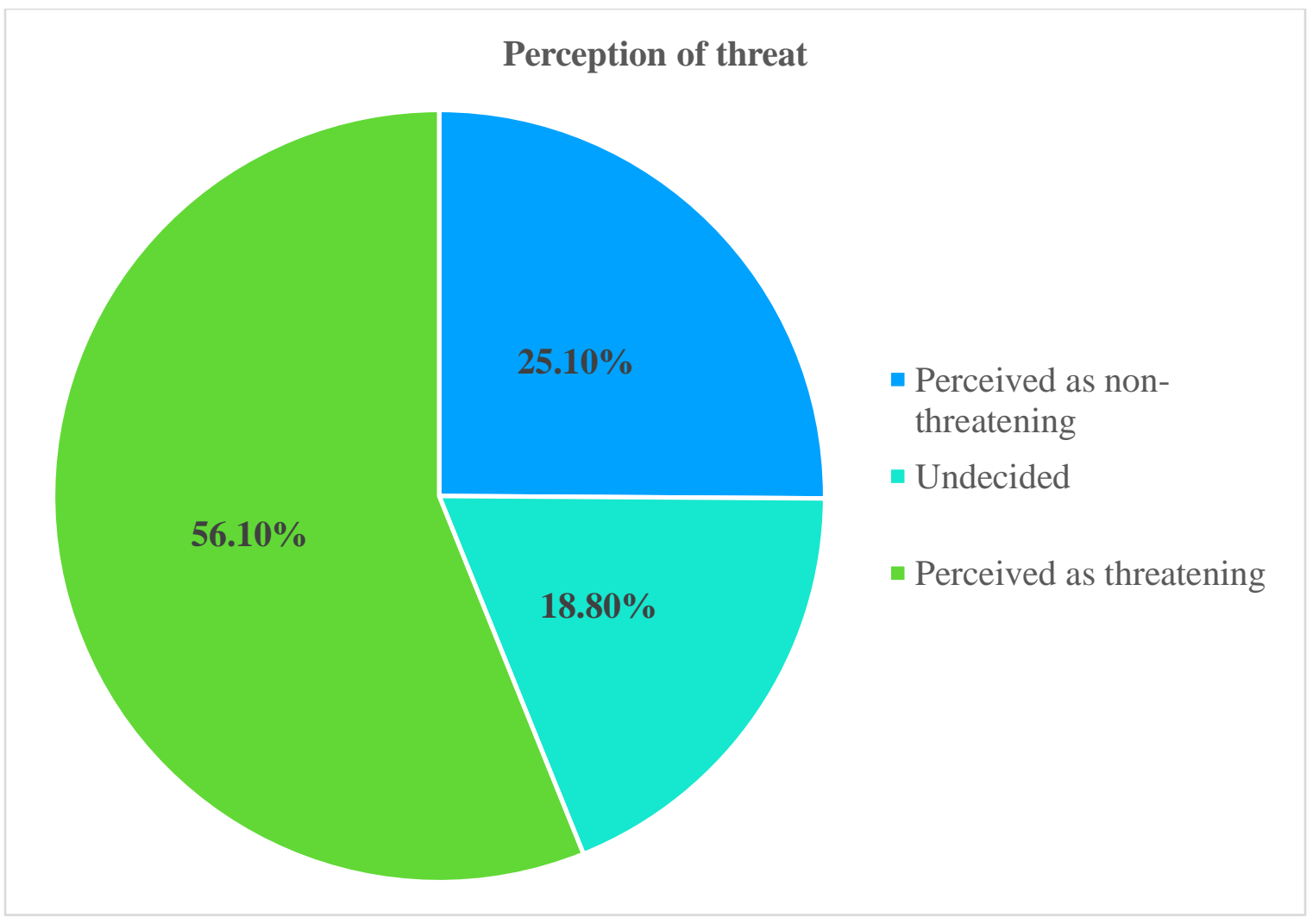


Perception of threat and public health behaviours

In the research, we examined the level of adherence and compliance with recommended public health measures across the country and investigated the particular relationship between perception of COVID-19 threat and emotional and behavioral responses at the individual level. More specifically, we investigated the relationship between perceptions of threat and adherence to specific and recommended public health measures as well as the relationship between perceptions of threat and the emotion of fear.

The data from Table 1 indicates high adherence to safety and health measures recommended by the WHO. The participants reported the highest compliance with washing hands for a minimum of 20 seconds $(\mathrm{M}=4.48, \mathrm{SD}=.83)$ and avoiding public gatherings measures $(\mathrm{M}=4.31, \mathrm{SD}=.93)$. Somewhat lower compliance was recorded with staying home and avoiding direct social contact measure $(\mathrm{M}=3.87, \mathrm{SD}=1.08)$. Moreover, the participants reported relatively significant support for public health initiatives. They characterized adherence to all implemented measures as important $(\mathrm{M}=3.96, \mathrm{SD}=1.13)$ and to the measure of social distancing, in particular $(\mathrm{M}=3.83, \mathrm{SD}=1.17)$. These results are presented in Table 2. As it can been seen from both tables reported below, participants, on average, reported high adherence to specific measures as well as stated that such adherence is highly imperative. The average scores were all above the mid-point of the scale (3). In addition and as it can be seen from the figure 2 below, the relationship between perceptions of threat and public health behaviors is statistically significant $(\mathrm{r}=.38, \mathrm{p}<.001)$ indicating that the more people perceived the pandemic threatening, the more likely they were to support and adhere to public health measures and recommendations.

Table 1

Mean values and standard deviations of reported adherence to measures of safety and health

\begin{tabular}{llc}
\hline & $\mathrm{M}$ & $\mathrm{SD}$ \\
\hline Washing hands for a minimum of 20 seconds, especially after & 4.48 & .83 \\
being in public spaces & & \\
Avoiding public gatherings & 4.31 & .93 \\
Staying home and avoiding direct social contact & 3.87 & 1.08
\end{tabular}

Note. $N=569 . M=$ Mean. $S D=$ Standard Deviation. Scores ranged from 1 to 5 . 
Table 2

Mean values and standard deviations of reported support for public health initiatives

M SD

Right now, the most important thing we can do is adhere to all pandemic

prevention measures

It is essential that we strictly adhere to the measures of social distancing until $\quad \begin{array}{lll}3.83 & 1.17\end{array}$ experts say otherwise

Note. $N=569 . M=$ Mean. $S D=$ Standard Deviation. Scores ranged from 1 to 5 .

Figure 2

Relationship between perceptions of threat and adherence to public health measures

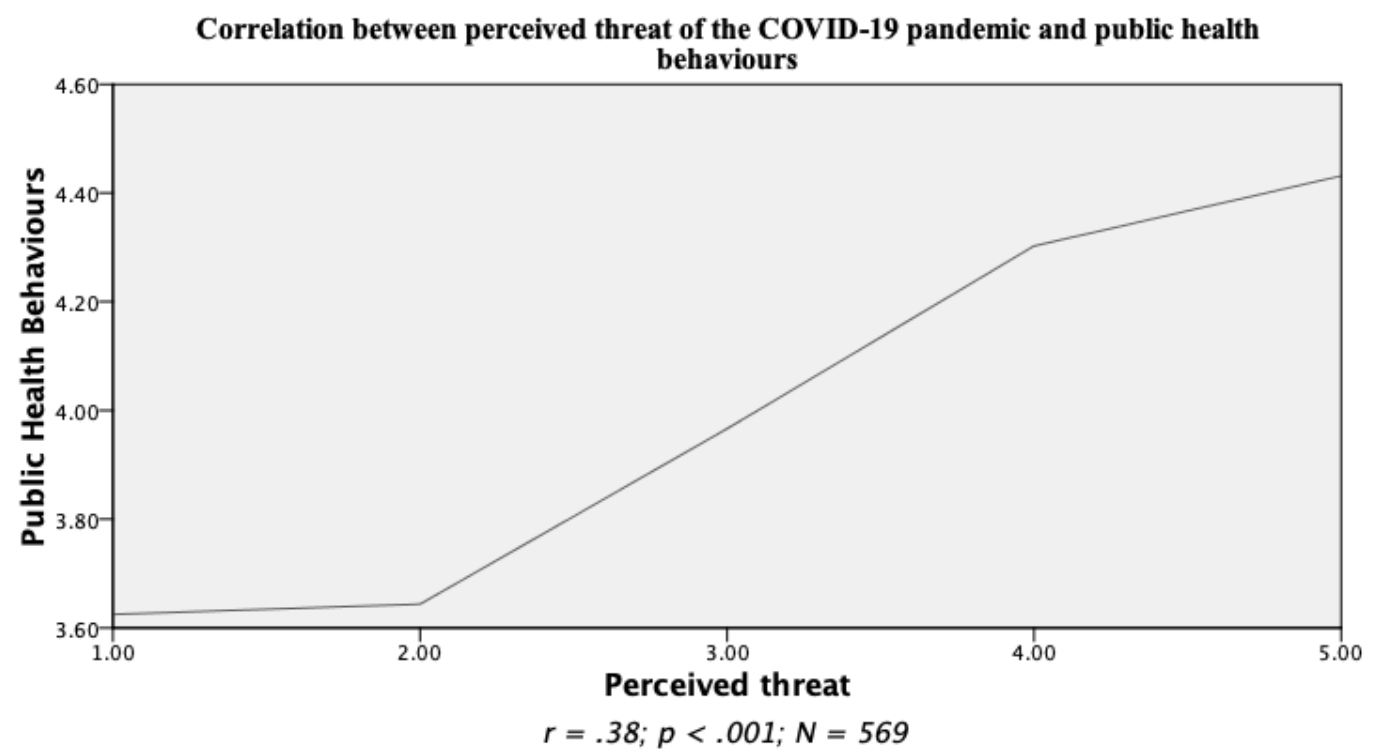


As indicated above, participants were asked to indicate the degree of trust they have towards relevant institutions. As it can be seen from the figure 3, participants reported extremely low levels of trust across all institutions with avereage levels being below the mid-point of the scale (3). Furtermore, level of trust (specific or combined) did not correlate in any meaningful way with public health behaviours indicating that it was not trust in governmental institutions that were driving the changes in behaviour but rather peoples' assessment of threat.

Figure 3

$$
\text { Reported levels of trust }
$$

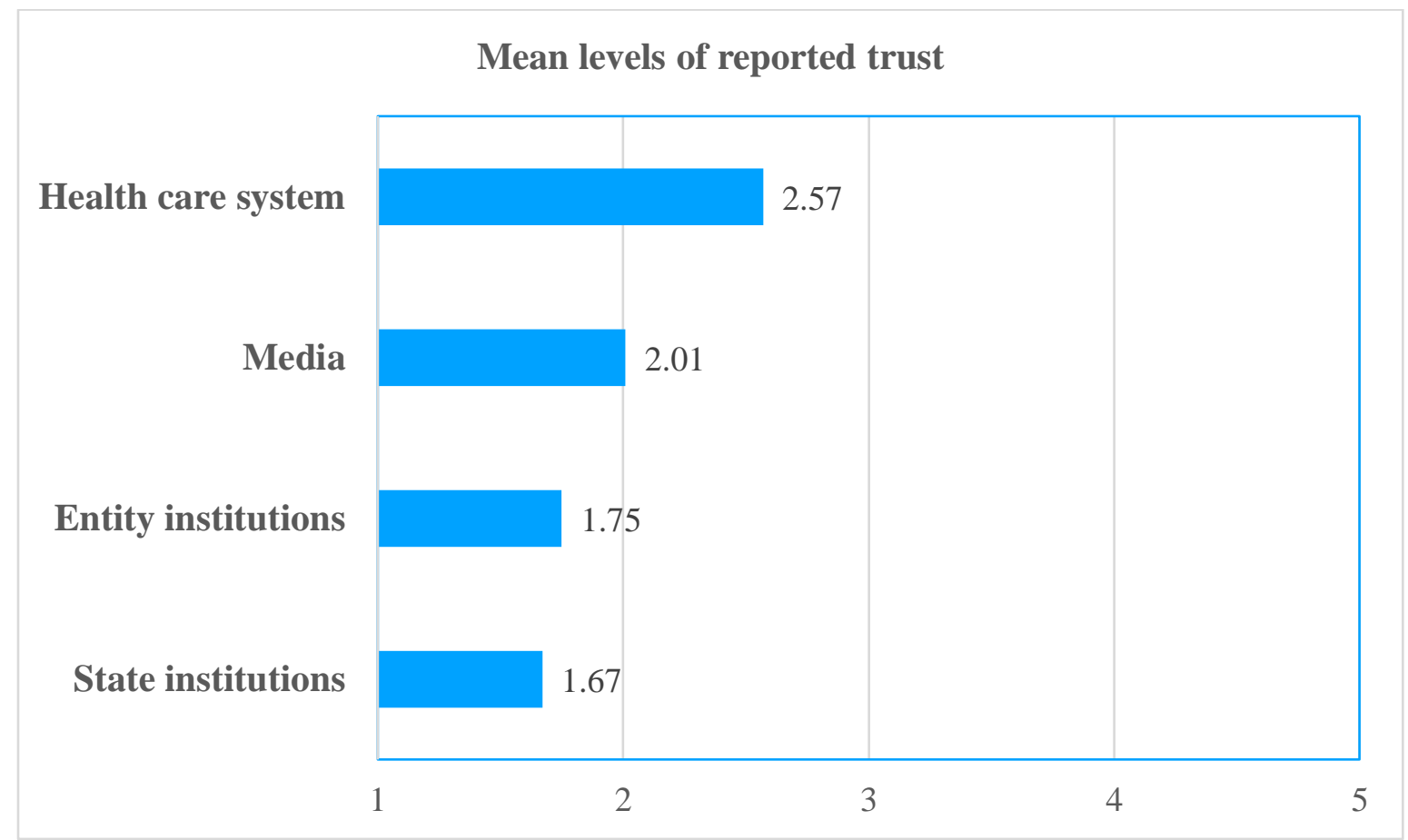

Reported stress levels

Overall, the participants did not report a high frequency of feeling stress symptoms during the peak of the pandemic in the country. Overthinking $(\mathrm{M}=3.62, \mathrm{SD}=1.35)$, change in sleep patterns $(\mathrm{M}=3.34, \mathrm{SD}=1.54)$, and nervousness $(\mathrm{M}=3.16, \mathrm{SD}=1.26)$ were the symptoms the participants experienced most frequently during that period. Consumptions of harmful substances $(\mathrm{M}=1.22, \mathrm{SD}=.70)$, consumption of alcohol $(\mathrm{M}=1.28, \mathrm{SD}=.76)$, and 
fear of death were the least frequent symptoms experienced by the participants $(\mathrm{M}=1.58, \mathrm{SD}$ $=.96)$. The overall results are presented in Table 4 .

Table 4

Mean values and standard deviations of reported stress symptoms

\begin{tabular}{llc}
\hline & $\mathrm{M}$ & $\mathrm{SD}$ \\
\hline Consumptions of other harmful substances & 1.22 & .70 \\
Consumption of alcohol & 1.28 & .76 \\
Fear of death & 1.58 & .96 \\
Consumption of cigarettes & 1.79 & 1.36 \\
Identity crisis & 1.96 & 1.29 \\
Fear of being forgotten & 1.98 & 1.23 \\
Indigestion or discomfort in abdomen & 2.17 & 1.30 \\
Fear of the worst happening & 2.35 & 1.24 \\
Loss of social connections & 2.48 & 1.26 \\
Loneliness & 2.63 & 1.33 \\
Inability to relax & 2.79 & 1.21 \\
Change in eating patterns & 2.90 & 1.46 \\
Nervousness & 3.16 & 1.26 \\
Change in sleep patterns & 3.34 & 1.54 \\
Overthinking & 3.62 & 1.35 \\
\hline Note. $N=569 . M$ & & \\
\hline
\end{tabular}

Note. $N=569 . \mathrm{M}=$ Mean. $S D=$ Standard Deviation. Scored ranged from 1 to 5 .

Unlike with public health behaviour measures, perception of threat was not related to overall stress indicators. In other words, perceiving the pandemic as more threatening did not lead participants to report higher levels of stress symptoms. However, perception of threat was significantly correlated with one specific stress indicator (fear of worst happening) with $r=$ $.15, \mathrm{p}<.001$. This indicates that perceiving the pandemic as more threatning was more likely to lead to an increase in reported fear. See figure 4 for the illustration of this particular relationship. 
Figure 4

Relationship between perceptions of threat and reported fear

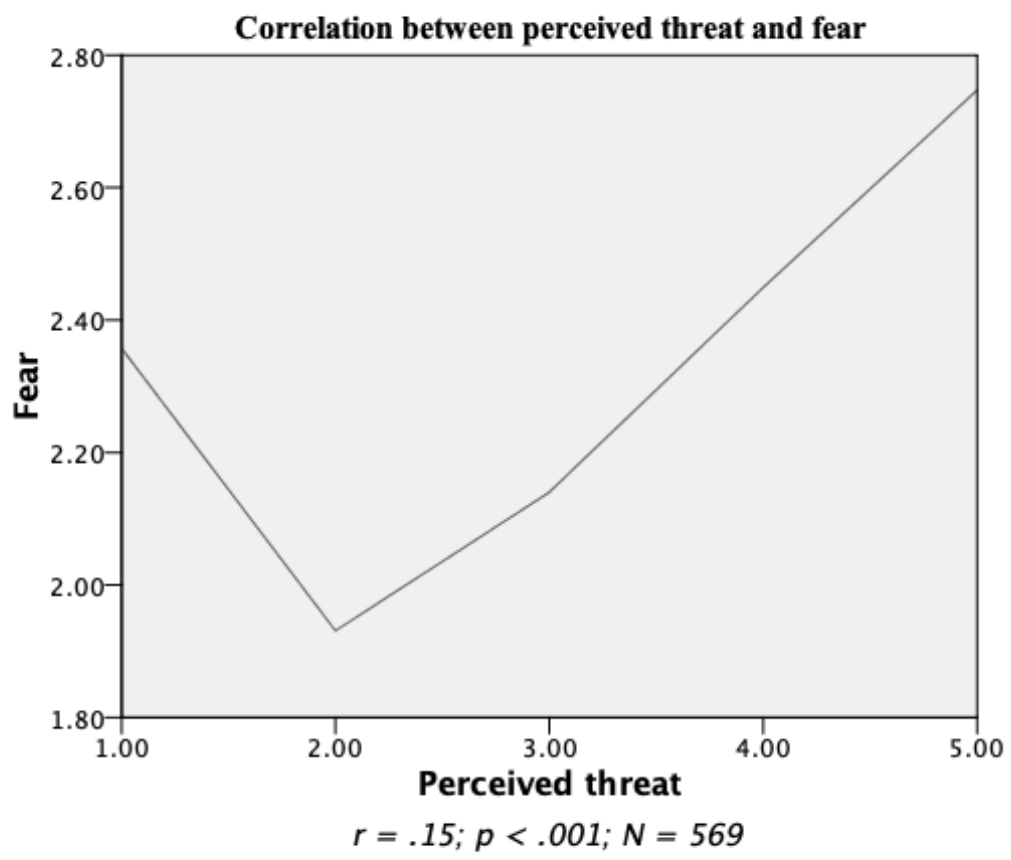

Social interactions

The results from Table 5 show that there was no significant increase in interest in politics $(\mathrm{M}=2.73, \mathrm{SD}=1.30)$ nor media consumption $(\mathrm{M}=2.96, \mathrm{SD}=1.31)$ during the pandemic. In addition, Table 6 demonstrates that a significant number of participants $(\mathrm{M}=$ $3.62, \mathrm{SD}=1.27$ ) gave more importance to family activities during isolation.

Table 5

Mean values and standard deviations of reported participation/passivity

\begin{tabular}{llc}
\hline & $\mathrm{M}$ & $\mathrm{SD}$ \\
\hline I am spending more time talking about politics with my friends since the & 2.73 & 1.30 \\
state of emergency has been declared & & \\
$\begin{array}{l}\text { I have been following the media much more since the pandemic has been } \\
\text { declared }\end{array}$ & & \\
\hline
\end{tabular}

Note. $M=$ Mean. $S D=$ Standard Deviation. 
Table 6

Mean values and standard deviations of reported importance of spending time with a family during the pandemic

\begin{tabular}{lll}
\hline & M & SD \\
\hline Family activities became more important during the isolation & 3.62 & 1.27
\end{tabular}

Note. $M=$ Mean. $S D=$ Standard Deviation.

Perception of threat and social cohesion

Closer inspection of Table 7 and Table 8 demonstrates a high level of social cohesion. When asked about whom they are mostly concerned about during this pandemic, a significant majority $(72.4 \%)$ of the participants answered that they are mostly concerned about all citizens of the country. Correspondingly, when asked if they could help, to which group they would mainly help, 54.1\% answered all people in the country, and $35.3 \%$ answered to the members of at-risk groups, which in total is $89.4 \%$.

Table 7

Frequency of reported concern about specific groups

\begin{tabular}{lll}
\hline & $\mathrm{N}$ & $\%$ \\
My neighborhood & 21 & $3.7 \%$ \\
My community & 111 & $19.5 \%$ \\
My entity & 25 & $4.4 \%$ \\
All citizens of my country & 412 & $72.4 \%$ \\
Total & $\mathbf{5 6 9}$ & $\mathbf{1 0 0 \%}$ \\
\hline
\end{tabular}

Table 8

Frequency of reported concern about specific groups

\begin{tabular}{lll}
\hline & $\mathrm{N}$ & $\%$ \\
\hline People in my community & 52 & $9.1 \%$ \\
Members of at-risk groups & 201 & $35.3 \%$ \\
Members of my ethnic / national group & 8 & $1.4 \%$ \\
All people in my state equally & 308 & $54.1 \%$ \\
Total & $\mathbf{5 6 9}$ & $\mathbf{1 0 0 . 0}$ \\
\hline
\end{tabular}




\section{Conclusion}

In this paper we reported data on some important social and behavioural responses from a sample of young people $(\mathrm{N}=569)$ of different ethnic backgrounds and from different parts of Bosnia and Herzegovina during the COVID-19 pandemic. Results suggest that people, on average are taking the pandemic serious enough, making them more likely to comply with public health measures such as handwashing and social distancing. This indicates that increased awareness about the risk has produced a favorable impact on compliance with the measures (e.g., Wise et al., 2020) . Furthermore, results indicate that it was perception of threat that predicted public health behaviours and support for public initiatives and not trust in relevant institutions (political trust) which was extremely low across all levels. Connecting these results with the existing literature, it could be argued that participants exhibit relatively high levels of self-efficacy leading threat perceptions to produce more constructive responses such as compliance and adherence to safety and health measures (Witte et al., 2000).

Furthermore, perception of threat was not related to stress indicators which were relativelely low despite social isolation and imposed physical restrictions. Correspondigly, the results show that perception of threat did not produce an unfavorable impact on the mental health of people. These patterns could be explained by an increased proximity and interaction with family members reducing a sense of social and emotional isolation. In addition, cultural factors such as individualism or interdependence could partially explain patterns and implications of more community and family intimite relationships.

On a positive end and in regard to social cohesion, participants reported relatively high levels of social cohesion including a relatively high identification with the entire country $(38.5 \%)$ - rather than speicfic ethnic groups. It could be argued that this particular pandemic, as a societal threat provided a sense of shared destiny leading people to expand their identity boundaries making it more inclusive all others. Sense of shared destiny might have led people to reorganize themselves and members of other ethnic groups into a single community. Such creation of common-ingroup identity category is more easier to establish in contexts where subgroups share equal status (Dovidio et al., 2007) as they do in the context of Bosnia and Herzegovina. Table 9 provides a summary of the main results. 
Table 9

Overall mean levels of main social and behavioural responses

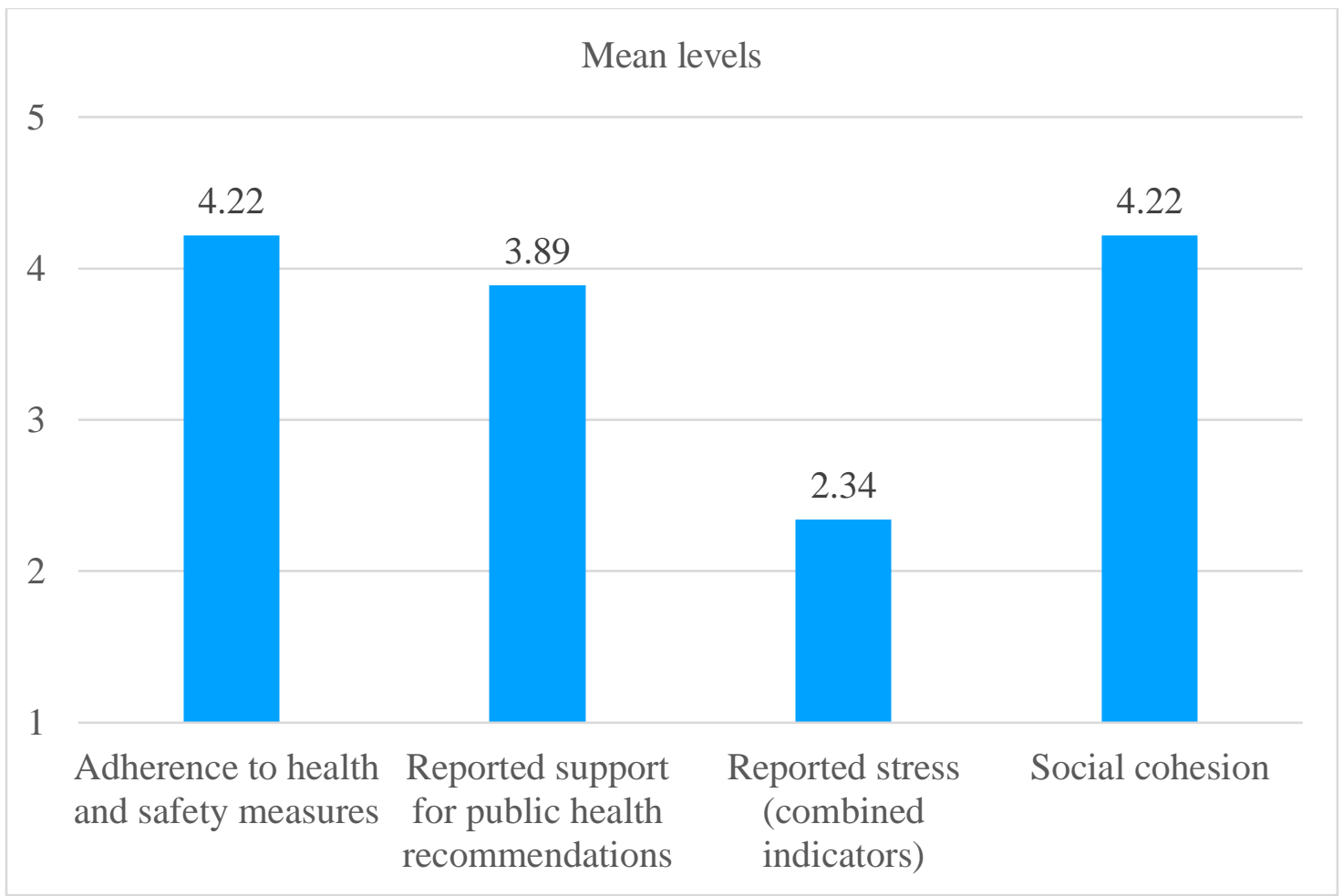




\section{References}

Abraham, Charles, and Paschal Sheeran. 2015. "The Health Belief Model." Pp. 30-69 in Predicting and Changing Health Behavior: Research and Practice with Social Cognition Models, Mark Conner and Paul Normaned (ed). Maidenhead: Open University Press.

Baumeister, Roy F., and Mark R. Leary. 1995. "The Need To Belong: Desire For Interpersonal Attachments As A Fundamental Human Motivatio." Psychological Bulletin 117(3):497-529.

Council of Ministers of Bosnia and Herzegovina. 2020. "Council Of Ministers Of Bosnia And Herzegovina Holds Its 5Th Extraordinary Session." Vijece ministara. Retrieved May

20 ,

2020

(http://www.vijeceministara.gov.ba/saopstenja/sjednice/saopstenja_sa_sjednica/default.aspx? $\mathrm{id}=32585 \&$ langTag=bs-BA).

Dovidio, J. F., Gaertner, S. L. \& Saguy, T. 2007. Another view of "we": majority and minority group perspectives on a common ingroup identity. European Review of Social Psychology 18, 296-330.

Hatfield, Elaine, John T. Cacioppo, and Richard L. Rapson. 1993. "Emotional Contagion." Current Directions in Psychological Science 2(3):96-100.

Khosravi, Mohsen. 2020. "Perceived Risk Of COVID-19 Pandemic: The Role Of Public Worry And Trust." Electronic Journal of General Medicine 17(4):em203

Kramer, Adam D. I., Jamie E. Guillory, and Jeffrey T. Hancock. 2014. "Experimental Evidence Of Massive-Scale Emotional Contagion Through Social Networks." Proceedings of the National Academy of Sciences 111(24):8788-8790.

N1. 2020. "Bosnia Confirms Its First Case Of Coronavirus." N1. Retrieved May 20, 2020 (http://ba.n1info.com/English/NEWS/a414110/Bosnia-confirms-its-first-case-ofCoronavirus.html).

Polizzi, Craig, Steven Jay Lynn, and Andrew Perry. 2020. "Stress And Coping In The Time Of COVID-19: Pathways To Resilience And Recovery." Clinical Neuropsychiatry 17(2):59-62.

Riek, B. M., Mania, E. W. \& Gaertner, S. L. (2006). Intergroup threat and outgroup attitudes: A meta-analytic review. Personality and Social Psychology Review, 10(4), 336-353.

Rogers, Ronald W. 1975. "A Protection Motivation Theory Of Fear Appeals And Attitude Change1." The Journal of Psychology 91(1):93-114. 
Stephan, Walter G. and Cookie White, Stephan. 2000. "An Integrated Threat Theory Of Prejudice." Pp. 23-45 in Reducing Prejudice and Discrimination, Stuart, Oskamped (ed). Mahwah, NJ: Lawrence Erlbaum Associates.

Van Bavel, Jay J. et al. 2020. "Using Social And Behavioural Science To Support COVID-19 Pandemic Response." Nature Human Behaviour volume 4:460-471.

Witte, Kim, and Mike Allen. 2000. "A Meta-Analysis Of Fear Appeals: Implications For Effective Public Health Campaigns." Health Education \& Behavior 27(5):591-615.

Wise, T., Zbozinek, T. D., Michelini, G., Hagan, C. C. \& Mobbs, D. Changes in risk perception and protective behavior during the first week of the COVID-19 pandemic in the United States. Preprint at PsyArXiv https://osf.io/dz428 (2020).

World Heatlh Organization. 2020a. "Rolling Updates On Coronavirus Disease (COVID-19)." World Health Organization. Retrieved June 1, 2020 (https://www.who.int/emergencies/diseases/novel-coronavirus-2019/events-as-they-happen).

World Health Organization. 2020b. "WHO Director-General's Opening Remarks At The Media Briefing On COVID-19 - 11 March 2020." World Health Organization. Retrieved May 20, 2020 (https://www.who.int/dg/speeches/detail/who-director-general-s-openingremarks-at-the-media-briefing-on-covid-19---11-march-2020).

World Health Organization. 2020c. "Coronavirus Disease 2019 (COVID-19) Situation Report - 51." World Health Organization. Retrieved May 20, 2020 (https://www.who.int/docs/default-source/coronaviruse/situation-reports/20200311-sitrep-51covid-19.pdf?sfvrsn=1ba62e57_10). 